\title{
Mitoxantrone Loaded Superparamagnetic Nanoparticles for Drug Targeting: A Versatile and Sensitive Method for Quantification of Drug Enrichment in Rabbit Tissues Using HPLC-UV
}

\author{
Rainer Tietze, Eveline Schreiber, Stefan Lyer, and Christoph Alexiou \\ Department of Otorhinolaryngology, Head and Neck Surgery, Friedrich-Alexander University Erlangen-Nürnberg, \\ Section for Experimental Oncology and Nanomedicine (Else Kröner-Fresenius-Foundation-Professorship), Waldstraße 1, \\ 91054 Erlangen, Germany \\ Correspondence should be addressed to Christoph Alexiou, c.alexiou@web.de
}

Received 21 October 2009; Accepted 25 February 2010

Academic Editor: Kazim Husain

Copyright () 2010 Rainer Tietze et al. This is an open access article distributed under the Creative Commons Attribution License, which permits unrestricted use, distribution, and reproduction in any medium, provided the original work is properly cited.

In medicine, superparamagnetic nanoparticles bound to chemotherapeutics are currently investigated for their feasibility in local tumor therapy. After intraarterial application, these particles can be accumulated in the targeted area by an external magnetic field to increase the drug concentration in the region of interest (Magnetic-Drug-Targeting). We here present an analytical method (HPLC-UV), to detect pure or ferrofluid-bound mitoxantrone in a complex matrix even in trace amounts in order to perform biodistribution studies. Mitoxantrone could be extracted in high yields from different tissues. Recovery of mitoxantrone in liver tissue $(5000 \mathrm{ng} / \mathrm{g}$ ) was $76 \pm 2 \%$. The limit of quantification of mitoxantrone standard was $10 \mathrm{ng} / \mathrm{mL} \pm 12 \%$. Validation criteria such as linearity, precision, and stability were evaluated in ranges achieving the FDA requirements. As shown for pilot samples, biodistribution studies can easily be performed after application of pure or ferrofluid-bound mitoxantrone.

\section{Introduction}

Application of chemotherapeutic agents bound to magnetic nanoparticles is a promising approach for site specific drug deposition. Magnetic-Drug-Targeting (MDT) is intended to elevate the drug concentration in the region of interest, because the drug loaded particles are enriched by a focused external magnetic field to defined body compartments after application [1-4]. This method can lead to both higher potency of antitumor treatments and reduction of negative side effects. In our model, drug loading was realized with mitoxantrone (MTO) (Figure 1), an anthracendion derivative which inhibits the DNA and RNA synthesis and causes DNA strand breaks by intercalation $[5,6]$. This active component was adsorptively bound to the iron oxide nanoparticles. This agent is used extensively in clinical trials to treat fatal diseases including leukemia, lymphoma, cancers of the breast and prostate [7], and to treat multiple sclerosis $[8,9]$.

A quantitative determination of the biodistribution of magnetic nanoparticles can be achieved by magnetorelax- ometry. The applicability of this technique for the quantification of ferrofluids (FF) in tissue has been demonstrated previously for an extracted tumor slice model [10], a specific artery model [11], and is even in process for the whole body distribution. MTO enrichment might be different, so we are interested in developing an easy multifunctional method to quantify the amount of MTO, especially if it is bound to coated nanoparticles.

Various methods have been described to extract MTO from blood plasma [12-16] and tissues [17] on its own. Moreover there are established protocols to determine MTO by HPLC measurements in context of drug delivery systems like liposome carriers [18] and nanosphere vehicles [19]. Protein precipitation with $0.5 \mathrm{M}$ hydrochloric acid: acetonitrile $(90: 10, \mathrm{v} / \mathrm{v})$, as described by Johnson et al. [18], leads to a recovery of pure MTO in porcine muscle tissue of more than $85 \%$ (Table 1). Nevertheless, measurement of MTO bound to iron oxide nanoparticles is more difficult, and extracting whole organs of white New Zealand rabbits this way was unfeasible. 
TABLE 1: Extraction of porcine muscle and liver tissues containing pure mitoxantrone (MTO) or MTO bound to ferrofluid (FF). The Table shows the high recovery rate of pure MTO and a lower recovery rate of FF-bound MTO in different tissues.

\begin{tabular}{|c|c|c|}
\hline Sample & Extraction modality ${ }^{(1)}$ & Recovery $[\%]^{(2)}$ \\
\hline $2 \mathrm{~g}$ liver $/ 100 \mu \mathrm{g}$ MTO & $2 \times \mathrm{MeOH}: 1 \mathrm{~N} \mathrm{HCl}=50: 50$ & $96 \pm 10$ \\
\hline $1 \mathrm{~g}$ muscle tissue $/ 100 \mu \mathrm{g}$ MTO & $2 \times 0,5 \mathrm{HCl}$ & $74^{(3)}$ \\
\hline $1 \mathrm{~g}$ muscle tissue $/ 100 \mu \mathrm{g}$ MTO & $2 \times \mathrm{MeCN}: 0,5 \mathrm{~N} \mathrm{HCl} 10: 90$ & $85 \pm 9$ \\
\hline $1 \mathrm{~g}$ muscle tissue $/ 100 \mu \mathrm{g}$ MTO & $2 \times \mathrm{MeOH}: 1 \mathrm{~N} \mathrm{HCl}=50: 50$ & $87 \pm 9$ \\
\hline $2 \mathrm{~g}$ muscle tissue $/ 100 \mu \mathrm{g} \mathrm{MTO}+500 \mu \mathrm{L}$ FF & $2 \times \mathrm{MeOH}: 1 \mathrm{~N} \mathrm{HCl}=50: 50$ & $64 \pm 7$ \\
\hline $1 \mathrm{~g}$ muscle tissue $/ 100 \mu \mathrm{g} \mathrm{MTO}+500 \mu \mathrm{L} \mathrm{FF}$ & $2 \times \mathrm{MeCN}: 0,5 \mathrm{~N} \mathrm{HCl} 10: 90$ & $79 \pm 8$ \\
\hline $2.5 \mathrm{~g}$ liver $/ 100 \mu \mathrm{g}$ MTO + $1 \mathrm{~mL}$ FF & $2 \times \mathrm{MeOH}: 1 \mathrm{~N} \mathrm{HCl}=50: 50$ & $56 \pm 27$ \\
\hline $2.5 \mathrm{~g}$ liver $/ 100 \mu \mathrm{g} \mathrm{MTO}+1 \mathrm{~mL}$ FF & $2 \times \mathrm{MeCN}: 1 \mathrm{~N} \mathrm{HCl}=10: 90$ & $58 \pm 15$ \\
\hline
\end{tabular}

${ }^{(1)}$ Typical extraction procedure: double incubation in ultrasonic bath, each for 10 minutes. Collecting the supernatant after centrifugation and HPLCmeasurement afterwards.

(2) number of independent experiments $n=3$

${ }^{(3)}$ single experiment.<smiles>O=C1c2c(O)ccc(O)c2C(=O)C2C(NCCNCCO)=CC=C(NCCNCCO)C12</smiles>

Figure 1: Structure of mitoxantrone (MTO).

Lu et al. developed a helpful method to determine MTO [19], which has been applied in the form of bovine serum albumin (BSA) nanospheres and revealed also promising results in our context. But in order to reliably capture even trace amounts of MTO, an optimization of the extraction mode has been necessary, as well as the development of a subsequent solid phase extraction (SPE) method. Here we present a newly developed method to determine MTO in different tissues and of different binding statuses.

\section{Experimental}

2.1. Chemicals. The analytical grade solvent, methanol, acetonitrile, chloroform were obtained from Carl Roth, Germany and Merck, Germany. Other chemicals were either delivered by Merck, Germany (formic acid, sodium formate, phosphoric acid, potassium dihydrogen phosphate, and citric acid), Carl Roth, Germany (trichloroacetic acid and sodium citrate dihydrate), or Sunlife, Germany (ascorbic acid). MTO was delivered by NeoCorp Pharma (Lot: 82056305, expiration date: 05/2010), Germany (test sample, a concentrate $(2 \mathrm{mg} / \mathrm{mL})$ to produce an injection solution).

The ferrofluids were synthesized according to a protocol by Hodenius [20].

2.2. HPLC. The HPLC analyses were performed by a Waters Alliance model consisting of a separation module (2695 series) and a dual wavelength absorbance detector (2487 series). The eluate was monitored at $254 \mathrm{~nm}$. The separation was carried out using a $3.0 \times 100 \mathrm{~mm}$ X-Bridge Phenyl column (Waters, Germany) with a particle diameter of $3.5 \mu \mathrm{m}$; the guard column consisted of the same material and was $3.0 \times 20 \mathrm{~mm}$ of size. The column temperature was $55^{\circ} \mathrm{C}$, the mobile phase was made up of buffer $(80 \mathrm{nM}$ sodium formate and formic acid, $\mathrm{pH} 3.0)$ and methanol $(80: 20 \mathrm{v} / \mathrm{v})$. Flow was $1 \mathrm{~mL} / \mathrm{min}$, the injection volume was $50 \mu \mathrm{L}$ at room temperature. All measurements were performed after an HPLC-method validation including selectivity, linearity, limit of quantification, precision, accuracy, recovery rate, and stability according to a validation protocol [21, 22]. Prior to the sample measurements, a calibration curve with MTOconcentrations of $10 \mathrm{ng} / \mathrm{mL}-20000 \mathrm{ng} / \mathrm{mL}$ was done.

2.3. Method Development/Optimization. For the extraction experiments, we used porcine muscle tissue and liver tissue which were doped with defined amounts of pure MTO or MTO bound to FF. This occurred by adding dissolved MTO at defined values (see Tables 1 and 2) to tissue homogenates and incubating overnight at room temperature. Due to the complexity of liver tissue and the successful determination here and moreover in muscle tissue, this method could be suitable to perform a complete biodistribution of MTO in rabbits. The extraction was a result of an optimization process. Liver or muscle tissue, doped with MTO, was homogenized for 1 minute using an Ultra Turrax apparatus (Ika, Staufen, Germany) to lyse the cell membranes prior to sonication. Several extraction mixtures containing hydrochloric acid or phosphoric acid in combination with $\mathrm{MeOH}$ were tested for extraction efficiency and their compatibility with the SPE procedures (see Tables 1 and 3 ). For the extraction, simple shaking for 4 or 24 hours was compared to vortex mixing and 1 to 4 -fold ultrasonic treatment with a duration of 1 hour each using an ultrasonic bath (US) (Bandelin Sonorex TK 52, Berlin, Germany, without temperature control) (Table 2).

An alternatively performed accelerated solvent extraction (ASE) was done with ASE 200 (Dionex, Idstein, Germany) at temperatures of $40^{\circ} \mathrm{C}$ and $80^{\circ} \mathrm{C}$ according to a protocol of 
TABLE 2: Comparison of different extraction techniques.

\begin{tabular}{|c|c|c|}
\hline Matrix $^{(1)}$ & Extraction mode ${ }^{(2)}$ & Recovery $[\%]^{(3)}$ \\
\hline MTO +0.5 g porcine liver & 1 fold vortexing 3 minutes & $22 \pm 4$ \\
\hline FF-MTO +0.5 g porcine liver & 1 fold vortexing 3 minutes & $26 \pm 4$ \\
\hline FF-MTO + 0.5 g porcine liver & 1 fold vortexing 3 minutes +5 minutes Ultrasound & $34 \pm 3$ \\
\hline FF-MTO $+0.5 \mathrm{~g}$ porcine liver & 4 hours shaking (Thermomixer Eppendorf Comfort 600 rpm) & $27 \pm 2$ \\
\hline FF-MTO +0.5 g porcine liver & 24 hours shaking (Thermomixer Eppendorf Comfort 600 rpm) & $18^{(4)}$ \\
\hline FF-MTO $+0.5 \mathrm{~g}$ porcine liver & $1 \times 1$ hour Ultrasound & $38 \pm 3$ \\
\hline FF-MTO + $0.5 \mathrm{~g}$ porcine liver & $1 \times 4$ hours Ultrasound & $31 \pm 5$ \\
\hline FF-MTO + 0.5 g porcine liver & $4 \times 1$ hour Ultrasound & $76 \pm 6$ \\
\hline FF-MTO + 5 g porcine liver & $\mathrm{ASE}^{(5)} 40^{\circ} \mathrm{C}, 1$ cycle & $36 \pm 6$ \\
\hline FF-MTO + 5 g porcine liver & $\operatorname{ASE}^{(5)} 80^{\circ} \mathrm{C}, 1$ cycle & $81 \pm 6$ \\
\hline \multicolumn{3}{|c|}{ 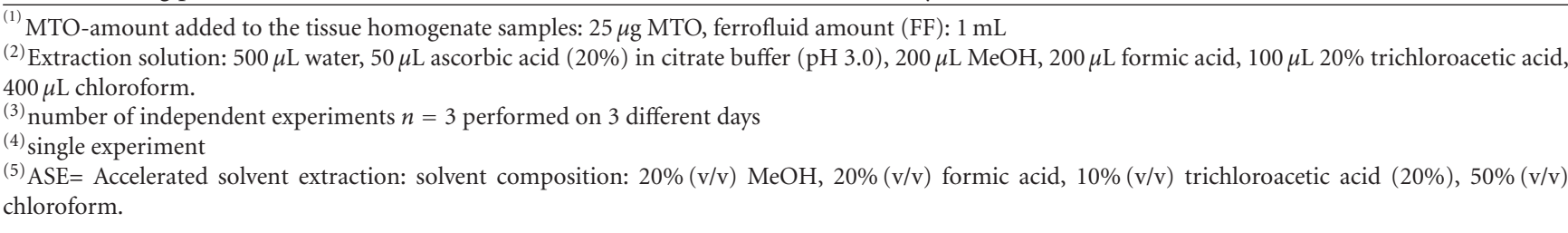 } \\
\hline
\end{tabular}

TABle 3: Mitoxantrone (MTO) recovery of pure MTO or MTO bound to ferrofluid (FF) in $2.5 \mathrm{~g}$ tissue using a RP-18-Cartridge. 1st section shows extractants based on hydrochloric acid, 2nd section shows phosphoric acid-based extractants, and 3rd section shows phosphate-buffer extractants. In general: FF-bound MTO in liver tissue exhibited insufficient recovery rates.

\begin{tabular}{|c|c|c|c|c|c|}
\hline & Cartridge & Matrix & Extraction mode $\mathrm{e}^{(3)}$ & $\begin{array}{l}\text { Condition/Elution- } \\
\text { mode }\end{array}$ & Recovery $[\%]^{(1)}$ \\
\hline \multirow{6}{*}{1 st } & No cartridge & FF-MTO & $1 \mathrm{~N} \mathrm{HCl}$ & No cartridge & $93^{(2)}$ \\
\hline & Sep-Pak-Plus C18 & MTO & $1 \mathrm{~N} \mathrm{HCl}$ & $1 \mathrm{~N} \mathrm{HCl} / \mathrm{MeOH}$ & $77 \pm 6$ \\
\hline & Sep-Pak-Plus C18 & $\begin{array}{l}\text { MTO + porcine muscle } \\
\text { tissue }\end{array}$ & $1 \mathrm{~N} \mathrm{HCl}$ & $\mathrm{H}_{2} \mathrm{O} / \mathrm{MeOH}$ & $67 \pm 2$ \\
\hline & Sep-Pak-Plus C18 & $\mathrm{MTO}+$ porcine liver & $1 \mathrm{~N} \mathrm{HCl}$ & $1 \mathrm{~N} \mathrm{HCl} / \mathrm{MeOH}$ & $41 \pm 11$ \\
\hline & Sep-Pak-Plus C18 & FF-MTO & $1 \mathrm{~N} \mathrm{HCl}$ & $1 \mathrm{~N} \mathrm{HCl} / \mathrm{MeOH}$ & $4 \pm 1$ \\
\hline & Sep-Pak-Plus C18 & FF-MTO + porcine liver & $1 \mathrm{~N} \mathrm{HCl}$ & $1 \mathrm{~N} \mathrm{HCl} / \mathrm{MeOH}$ & $9 \pm 8$ \\
\hline \multirow{4}{*}{ 2nd } & No Cartridge & FF-MTO & $0.1 \mathrm{M} \mathrm{H}_{3} \mathrm{PO}_{4}$ & No Cartridge & $94^{(2)}$ \\
\hline & Sep-Pak-Plus C18 & FF-MTO & $0.1 \mathrm{M} \mathrm{H}_{3} \mathrm{PO}_{4}$ & $1 \mathrm{~N} \mathrm{HCl} / \mathrm{MeOH}$ & $74 \pm 10$ \\
\hline & Sep-Pak-Plus C18 & $\mathrm{MTO}+$ porcine liver & $0.1 \mathrm{M} \mathrm{H}_{3} \mathrm{PO}_{4}$ & $0,1 \mathrm{M} \mathrm{H}_{3} \mathrm{PO}_{4} / \mathrm{MeOH}$ & $76 \pm 10$ \\
\hline & Sep-Pak-Plus C18 & FF-MTO + porcine liver & $0.1 \mathrm{M} \mathrm{H}_{3} \mathrm{PO}_{4}$ & $\mathrm{MeOH} / 0,1 \mathrm{M} \mathrm{H}_{3} \mathrm{PO}_{4}$ & $12 \pm 8$ \\
\hline \multirow[t]{2}{*}{$3 r d$} & Sep-Pak-Plus C18 & FF-MTO + porcine liver & $\begin{array}{c}0.1 \mathrm{M} \mathrm{KH}_{2} \mathrm{PO}_{4} / \mathrm{H}_{3} \mathrm{PO}_{4} \\
(\mathrm{pH}=6.0)\end{array}$ & $1 \mathrm{~N} \mathrm{HCl} / \mathrm{MeOH}$ & n.d. ${ }^{(4)}$ \\
\hline & Sep-Pak-Plus C18 & FF-MTO + porcine liver & $0.1 \mathrm{M} \mathrm{KH}_{2} \mathrm{PO}_{4} / \mathrm{HCl}$ & $1 \mathrm{~N} \mathrm{HCl} / \mathrm{MeOH}$ & $17 \pm 16$ \\
\hline
\end{tabular}

${ }^{(1)}$ number of independent experiments $=3$

(2) single experiment

${ }^{(3)}$ Typical extraction procedure: double incubation in ultrasonic bath each for 10 minutes. Collecting the supernatant after centrifugation and HPLCmeasurement afterwards

${ }^{(4)}$ Not detectable.

Klejdus et al. [23]. The cycle time was 10 minutes and just one cycle for each sample was performed.

To sum up, each $0.5 \mathrm{~g}$ MTO-containing tissue was treated 4 times for 1 hour with ultrasound in the extraction mixture ( $500 \mu \mathrm{L}$ water, $50 \mu \mathrm{L}$ ascorbic acid (20\%) in citrate buffer $(\mathrm{pH}$ 3.0) $200 \mu \mathrm{L}$ methanole (MeOH), $200 \mu \mathrm{L}$ formic acid, $100 \mu \mathrm{L}$, $20 \%$ trichloroacetic acid, $400 \mu \mathrm{L}$ chloroform) followed by centrifugation for 10 minutes at $8000 \times \mathrm{G}$ (Jouan MR $23 \mathrm{I}$, Germany). The combined supernatant was concentrated via a Bond Elut Plexa $(200 \mathrm{mg}, 6 \mathrm{~mL}$, Varian, Darmstadt, Germany) cartridge after conditioning with acetonitrile $(\mathrm{MeCN})$ and $2 \%$ formic acid in water. The analyte was eluted with $5 \mathrm{~mL} \mathrm{2 \%} \mathrm{formic} \mathrm{acid} \mathrm{in} \mathrm{MeCN}$ and dried under airstream. The water resolved residue was measured by HPLC as described above to display the efficiency of the extraction.

\section{Results and Discussion}

3.1. Optimization of the Extraction. In terms of drug delivery with nanoparticles, only traces of MTO are embedded in different tissues so that the whole organ has to be processed. The extraction of MTO using $1 \mathrm{~N}$ hydrochloric acid $(\mathrm{HCl})$, 


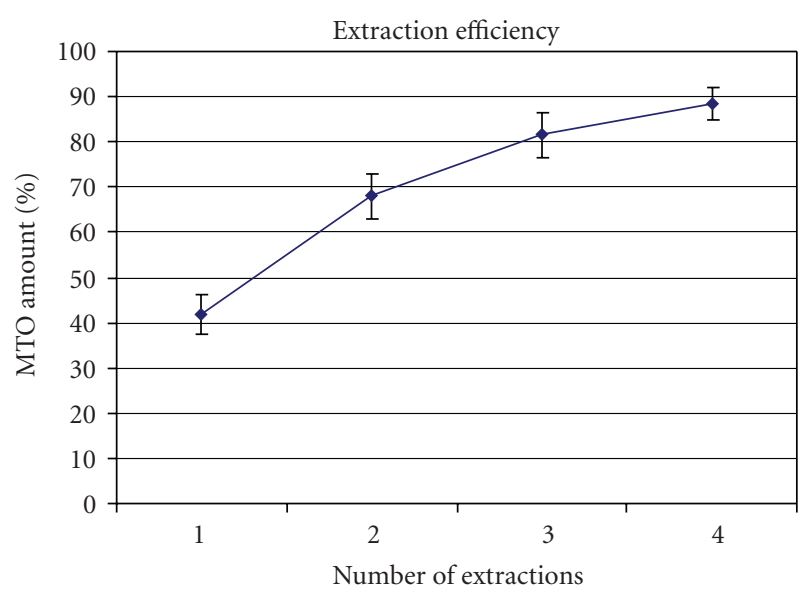

Figure 2: Extraction efficiency: extraction with: $500 \mu \mathrm{L}$ water, $200 \mu \mathrm{L} \mathrm{MeOH}, 50 \mu \mathrm{L}$ ascorbic acid (20\%) in citrate buffer ( $\mathrm{pH} 3.0$ ), $200 \mu \mathrm{L}$ formic acid, $100 \mu \mathrm{L} 20 \%$ trichloroacetic acid, and $400 \mu \mathrm{L}$ chloroform in an ultrasonic bath. Recovery rate in dependence to multiple extractions. 4 fold extraction is nearly quantitative. Each reading point was measured in triplicate.

$\mathrm{MeOH} / 1 \mathrm{~N} \mathrm{HCl}(50: 50 \mathrm{v} / \mathrm{v})$, or $1 \mathrm{~N} \mathrm{HCl} / \mathrm{MeCN}(90: 10 \mathrm{v} / \mathrm{v})$ was efficient for extracting pure MTO (Table 1). When it was bound to FF, the yield decreased significantly. Since a onephase-extraction led to turbid, protein-rich supernatants, protein precipitation by trichloroacetic acid (TCA) as well as Carrez-clearing [24] were used. Unfortunately, both methods did not show promising results. Especially, Carrez-clearing even leads to a blue coprecipitate of MTO.

A new point of view offered the extraction mode of $\mathrm{Lu}$ et al. [19] with a two-phase-extraction system to separate interfering lipophilic substances in organs, especially liver tissue. This method gave also the possibility to precipitate the protein fraction and save MTO from decomposition. Nevertheless, we modified this method because more tissue and less MTO required an optimization. We used homogenization for 1 minute via Ultra Turrax (Ika) to dehisce the cell membranes prior to sonication. Simple vortexing and just one single extraction cycle obtained only $26 \%$ recovery (Table 2). Ultrasonic extraction was superior to simple vortexing, and multistep-extraction even increased the efficiency. A 4 -fold extraction each for 1 hour was nearly quantitative $(88 \pm 4 \%)$ (Figure 2$)$.

Of course, the accelerated solvent extraction (ASE) (Table 2) method led to high extraction rates in short time but this is very expensive. Moreover, ASE tends to require also a useful SPE processing afterwards.

3.2. Combination of Extraction and Cartridge Procedure. To quantify the MTO amount of a whole organ, a useful SPE method was necessary. Unfortunately all the extraction modes described in Table 1 lead to turbid, protein-rich supernatants clogging the SPE cartridge. Using the RP18 Cartridge (Sep-Pak-Plus C18, $360 \mathrm{mg}$, Waters) and a standard elution procedure with water and $\mathrm{MeOH}$, recovery of MTO was not sufficient although pretesting with pure
MTO gave promising results ( $>90 \%$ ) (Table 3 ). A recovery rate of $76 \%$ by extraction of MTO in porcine liver tissue with phosphoric acid was adequate (Table 3 ). It is also possible to extract, fixate, and elute MTO bound to FF when using phosphoric acid or phosphate; but in the presence of liver tissue, the recovery of MTO connected to FF was scarce after the elution from the cartridge. In that case, extraction mixtures lead at the most to $17 \%$ recovery and almost no reproducibility. This was also true when hydrochloric acid was used for the extraction. The FF dissolved under these conditions and interestingly only traces of MTO could be detected, no matter what kind of conditioning mode was used for the SPE.

The choice of the right cartridge was essential. The widespread used RP-18 cartridge seemed to be not useful in our context. Most of the tested cartridges perform the fixation and elution of released MTO bound to FF, but in presence of liver tissue only Varian Bond Elut Plexa gave appropriate yields with more than $80 \%$ recovery (Table 4 ).

To sum up, the whole method entails a 1-hour ultrasonic extraction repeated $3 \times$ of tissue with the 2 -phase extractionsolution followed by concentration and purification via Varian Bond Elut Plexa cartridge and the consecutive HPLC measurement (Figure 3).

\subsection{Validation Procedure}

3.3.1. Selectivity. Chromatograms obtained from processed blank liver tissue did not show interfering peaks at the retention time of pure MTO measured by HPLC as seen in Figure 4. Selectivity was proved from 6 blank animals using their liver, lung, kidneys and muscle tissue. Each extraction was measured 5 times via HPLC. The results have to be observed in detail. Kidney, lung, and muscle tissue show a baseline chromatographic resolution of at least 1.5 from all other sample components and can be declared as fully separated. This criterion cannot be achieved for liver. The deficient baseline resolution could influence the analyte response. Experiments were performed to evaluate to what extend the impurity peak will affect the final assay result. 6 extraction solutions doted with MTO at the same amount, as the impurity peak is responding to $(100 \mathrm{ng} / \mathrm{mL})$, were concomitant analysed with identical amount of $100 \mathrm{ng} / \mathrm{mL}$ MTO in mobile phase solution. $T$-test of these 2 different population means gave the result that the impurity peak influences the respond significantly. To meet the specific criteria that nonseparable impurity peaks influence the result at most for $0.5 \%$ MTO [25], amounts more than $250 \mathrm{ng} / \mathrm{mL}$ can seriously be quantified.

3.3.2. Linearity and Lowest Limit of Quantification (LLOQ). 5 independent sets of calibration standards including blank samples have been prepared comprising values from $10 \mathrm{ng} / \mathrm{mL}$ to $20000 \mathrm{ng} / \mathrm{mL}$ pure MTO $(0,10,20,50,100$, $1000,2000,5000,10000,20000 \mathrm{ng} / \mathrm{mL}$ ); the $10 \mathrm{ng} / \mathrm{mL}$ standard was detected as the Lowest Limit of Quantification (LLOQ). The maximum deviation of the back calculated values for the LLOQ was $11.8 \%$ and $13.4 \%$ for reading points 


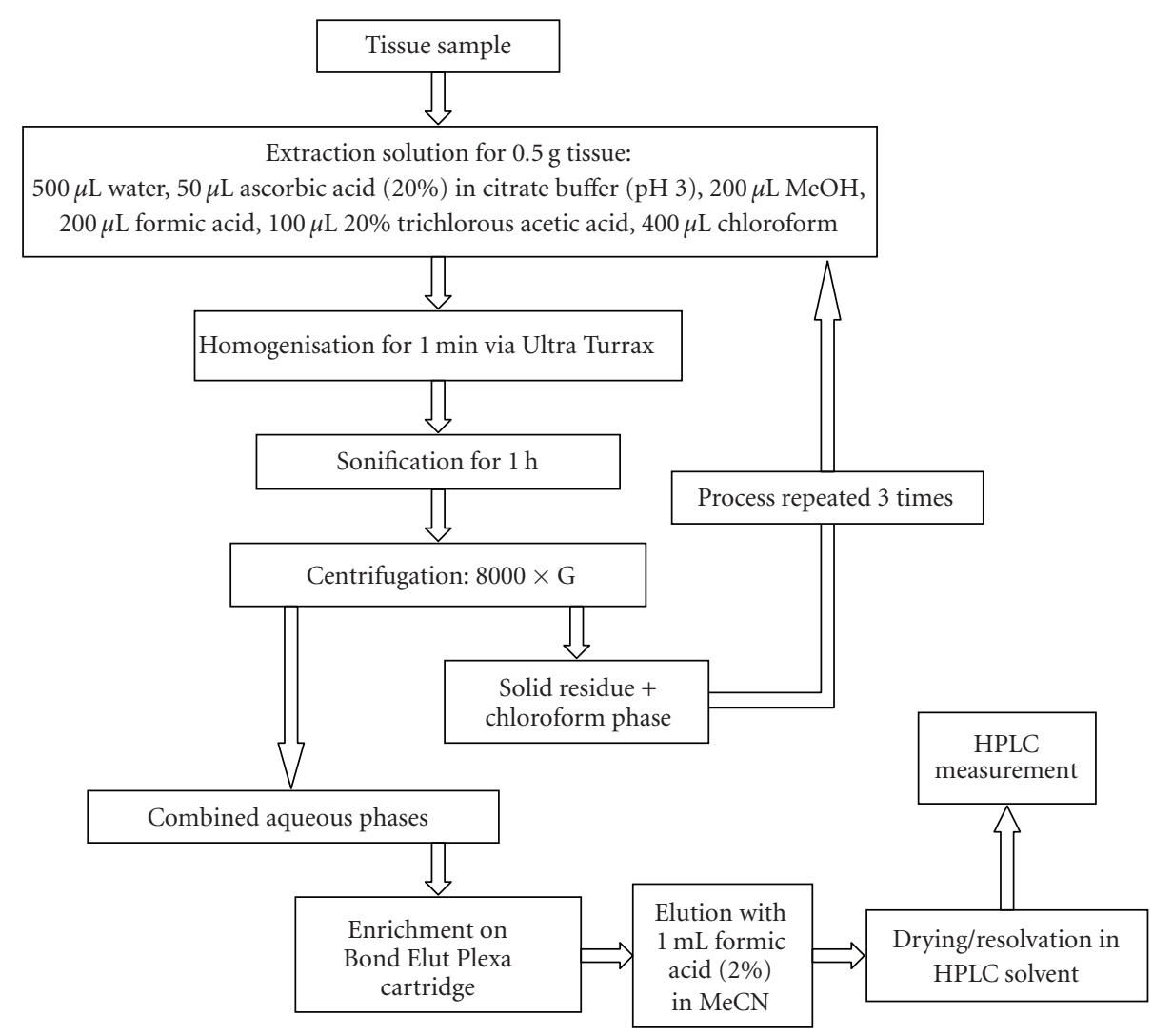

FIGURE 3: Flow chart of the whole method how to determine MTO in tissue: flow chart of the whole method how to determine MTO in tissue.

TABLE 4: Recovery of MTO after extraction of different matrices using different cartridges. Results vary extraordinarily, FF-bound MTO in liver tissue requires special solid phase.

\begin{tabular}{|c|c|c|c|}
\hline Matrix & Cartridge & Cartridge treatment after extraction ${ }^{(1)}$ & Recovery [\%] \\
\hline FF-MTO & Chromabond HR-X (Machery\&Nagel) & Water, $\mathrm{MeOH}$ & $21,2 \%$ \\
\hline FF-MTO & Chromabond HR-X (Machery\&Nagel) & $1 \mathrm{~N} \mathrm{HCl}, \mathrm{MeOH}$ & $22 \%$ \\
\hline FF-MTO & Oasis MCX (Waters) & $\begin{array}{l}\mathrm{HCOOH}(2 \%), \mathrm{MeOH} \text {, Elution with } \\
5 \% \mathrm{NH}_{3}\end{array}$ & $0,9 \%$ \\
\hline FF-MTO & LiChrolut En (Merck) & Water, $\mathrm{MeOH}$ & $89 \pm 5$ \\
\hline \multirow{2}{*}{ FF-MTO } & 1: Bond Elut PPL (Varian) & $\begin{array}{l}\mathrm{MeOH}, \mathrm{HCOOH}(2 \%) . \\
\text { Rinse with } \mathrm{HCOOH}(2 \%) .\end{array}$ & $1: 75 \%$ \\
\hline & 2: Bond Elut Plexa (Varian) & $\begin{array}{l}\text { Elution with }(2 \%) \mathrm{HCOOH} \text { in } \\
\text { MeOH. }\end{array}$ & $2: 81 \%$ \\
\hline $\begin{array}{l}\text { FF-MTO + } 0.5 \mathrm{~g} \\
\text { porcine Liver }\end{array}$ & Sep-Pak-Plus C18 (Waters) & $\mathrm{MeOH}, 1 \mathrm{~N} \mathrm{HCl}$ & $7 \pm 2$ \\
\hline $\begin{array}{l}\text { FF-MTO + } 0.5 \mathrm{~g} \\
\text { porcine Liver }\end{array}$ & LiChrolut En (Merck) & Water, $\mathrm{MeOH}$ & n.d. ${ }^{(2)}$ \\
\hline \multirow{2}{*}{$\begin{array}{l}\text { FF-MTO + } 0.5 \mathrm{~g} \\
\text { porcine Liver }\end{array}$} & 1: Bond Elut PPL (Varian) & $\begin{array}{l}\mathrm{MeOH}, \mathrm{HCOOH}(2 \%) . . \\
\text { Rinse with } \mathrm{HCOOH}(2 \%) .\end{array}$ & $1: 31 \%$ \\
\hline & 2: Bond Elut Plexa (Varian) & $\begin{array}{l}\text { Elution with }(2 \%) \mathrm{HCOOH} \text { in } \\
\mathrm{MeOH}\end{array}$ & $2: 86 \%$ \\
\hline
\end{tabular}

\footnotetext{
${ }^{(1)}$ Three times extracting with: $500 \mu \mathrm{L}$ water, $200 \mu \mathrm{L} \mathrm{MeOH}, 50 \mu \mathrm{L}$ ascorbic acid (20\%) in citrate buffer (pH 3.0), $200 \mu \mathrm{L}$ formic acid, $100 \mu \mathrm{L} 20 \%$ trichloroacetic acid, $400 \mu \mathrm{L}$ chloroform in an ultrasonic bath.

${ }^{(2)}$ n.d.: not detectable. MTO could not be fixated on the cartridge.
} 


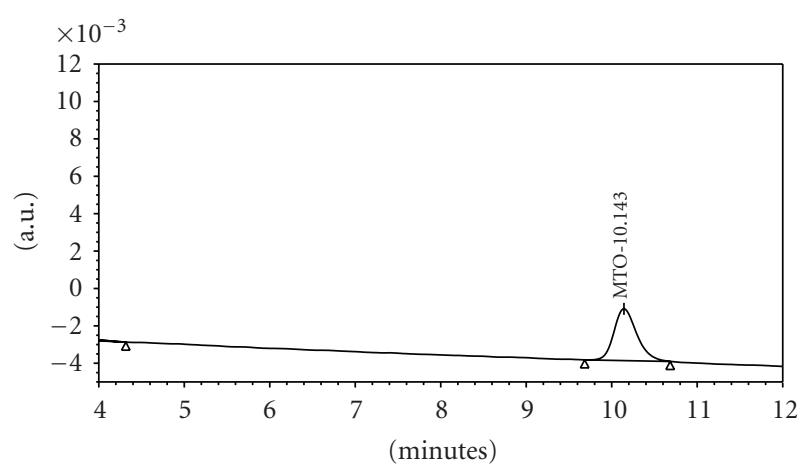

(a)

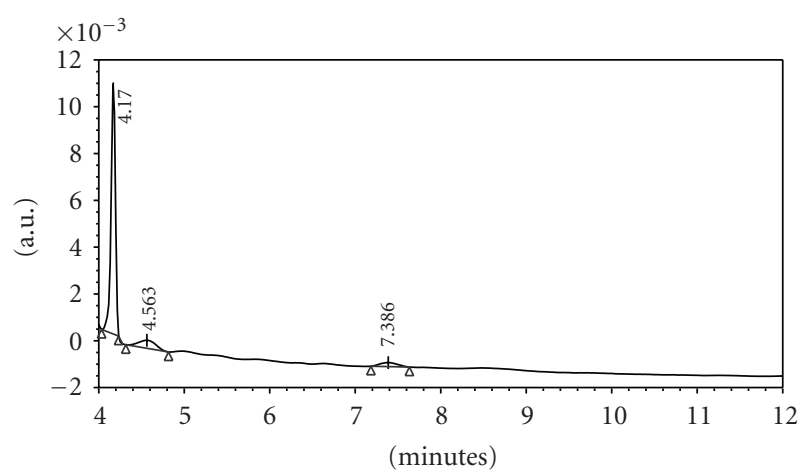

(b)

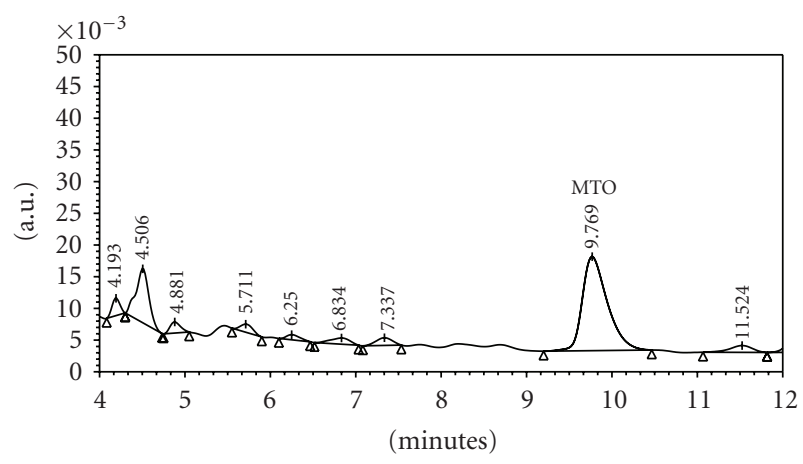

(c)

FIGURE 4: (a) HPLC-chromatogram of pure mitoxantrone (MTO $200 \mathrm{ng} / \mathrm{mL}$ ), (b) HPLC-chromatogram of processed blank liver tissue. No interfering peak at the retention time is determined for MTO. Chromatographic Conditions: $3.0 \times 100 \mathrm{~mm}$ X-Bridge Phenyl column (Waters, Germany), flow: $1 \mathrm{~mL} / \mathrm{min}$, mobile phase: buffer ( $80 \mathrm{nM}$ sodium formate and formic acid, $\mathrm{pH} 3.0)$ and methanol $(80: 20 \mathrm{v} / \mathrm{v})$. Column temperature $55^{\circ} \mathrm{C}$, injection volume $50 \mu \mathrm{L}$, UV-detection: $254 \mathrm{~nm}$. (c) HPLC-chromatogram of processed liver tissue containing MTO bound to ferrofluids. MTO is at retention time 9,77 .

unlike the LLOQ. The deviation of each reading point meets the FDA specification for linearity of $\pm 15 \%$ (LLOQ $\pm 20 \%$ ). For quantification of unknown samples, a linear equation without any weighting was used. Goodness of fit was not evaluated, because the correlation coefficient with more than 0.999 guarantees a sufficient linear correlation between MTO concentration and analytical response over the whole range (Figure 5). The LLOQ was determined according to the

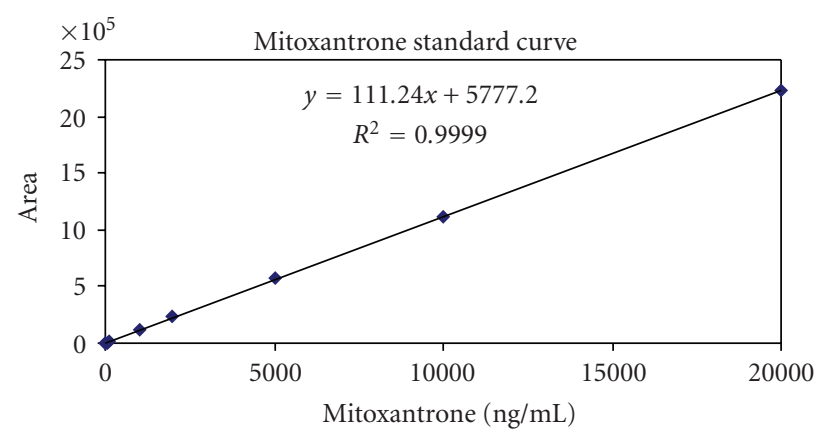

Figure 5: Mitoxantrone standard curve.

guidelines of FDA for bioanalytical method validation and is defined as the 5-time response compared to blank samples. This applies to the level of $10 \mathrm{ng} / \mathrm{mL}$ [21].

3.3.3. Precision. Intraassay precision is determined for 3 concentrations of pure MTO (5000; 10000 and $15000 \mathrm{ng} / \mathrm{mL}$ ). Each level was measured 5 times. The Level for $5000 \mathrm{ng} / \mathrm{mL}$ gave $1.0 \%$ relative standard deviation, the according data for the $10000 \mathrm{ng} / \mathrm{mL}$ and $15000 \mathrm{ng} / \mathrm{mL}$ levels are $0.9 \%$ and $1.0 \%$, respectively. Interassay precision was performed on 5 different days for the same values mentioned for intraassay. The relative standard deviations were: $1.4 \%$ for $5000 \mathrm{ng} / \mathrm{mL}$, $8.6 \%$ for $10000 \mathrm{ng} / \mathrm{mL}$ and $2.4 \%$ for $15000 \mathrm{ng} / \mathrm{mL}$.

3.3.4. Accuracy. Intraassay accuracy is determined for 3 concentrations of unbound MTO (5000, 10000, and $15000 \mathrm{ng} / \mathrm{mL}$ ). Each level was measured 5 times. The Level for $5000 \mathrm{ng} / \mathrm{mL}$ gave a deviation of the mean from the true value of $1.4 \%$; for $10000 \mathrm{ng} / \mathrm{mL}$ measurements gave $1.7 \%$ and $1.8 \%$ for $15000 \mathrm{ng} / \mathrm{mL}$, respectively and so meet the criteria which are $80-120 \%$ for the target concentration. The same experiments have been performed as interassay accuracy. Measurements mentioned above were arranged on 5 different days. The accuracy values (deviation of the mean from the true value) were $2.1 \%$ for $5000 \mathrm{ng} / \mathrm{mL}, 5.6 \%$ for $10000 \mathrm{ng} / \mathrm{mL}$, and $0.3 \%$ for $15000 \mathrm{ng} / \mathrm{mL}$.

3.3.5. Recovery Rate. Liver tissue was used exemplarily to evaluate the recovery rate with variable tissue and MTO amounts. The recovery rate of MTO in $5 \mathrm{~g}$ liver tissue was evaluated for 3 different MTO concentrations. Series A was doped with $25 \mu \mathrm{g}$, series B contained $2.5 \mu \mathrm{g}$, and series C $0.25 \mu \mathrm{g}$ MTO bound to FF. The experiments were performed in 3 independent experiments and measured in triplicate. The total recovery rate (extraction and SPE) for MTO in liver tissue for series A (5000 ng/g) was $76 \pm 2 \%$ for series B (500 ng/g) $67 \pm 5 \%$ and for series C (50 ng/g) $68 \pm 4 \%$.

The experiments were performed for 3 independent samples keeping in mind that the recovery can be different when using other tissues than liver. For biodistribution, recovery depends on the total weight of organs. The bigger the organs are the more MTO can be extracted in comparison to smaller organs having the same drug concentration. 
TABLe 5: Amount of MTO in different tissues after intravenous application of ferrofluid-bound MTO. New Zealand White rabbits $(n=5)$ were treated with $10 \%$ of the systemic necessary dose (10 $\mathrm{mg} / \mathrm{m}^{2}$ body surface).

\begin{tabular}{lc}
\hline Tissue & Detected MTO [ng] per g tissue ${ }^{(1)}$ \\
\hline Lung & $30 \pm 17$ \\
Liver & $89 \pm 22$ \\
Kidneys & $537 \pm 94$ \\
Muscle tissue & $1.4 \pm 0.7^{(2)}$ \\
\hline (1) deviation calculated as sem (standard error of the mean) \\
${ }^{(2)}$ concentration below the quantitation limit.
\end{tabular}

3.3.6. Stability. Processing the MTO-containing samples, the extraction from tissue material and SPE afterwards can lead to fragmentation of the analyte. We proved the stability of MTO by treating MTO and MTO bound to ferrofluids in the extraction solution ( $12500 \mathrm{ng} \mathrm{MTO} / \mathrm{mL}$ ) for 3 hours in an ultrasonic bath. Reprocessing using Bond Elut Plexa (Varian) cartridges lead to recovery of $85 \pm 1 \%(n=3)$ in case of pure MTO samples and $89 \pm 1 \%(n=3)$ in case of ferrofluidbound MTO samples. The deficit of the MTO amounts is owed to the cartridge procedure.

3.4. Pilot Experiments in order to Perform Biodistribution Studies. We used the method, described above with $4 \times$ 1 hour ultrasonic extraction (Figure 3), to measure the biodistribution of MTO in rabbits (New Zealand White, Charles River Corp., Germany) after intravenous (i.v.) application within a pilot study. For the experiments, New Zealand White Rabbits were used in accordance with the responsible authority (Regierung von Mittelfranken, request: 54-2531.31-27/06 approved in April 2007). The animals, weighing about $4.5-5.2 \mathrm{~kg}$, were treated with ferrofluidbound MTO containing a drug amount of $10 \%$ to the regular systemic dose which requires $10 \mathrm{mg} \mathrm{MTO} / \mathrm{m}^{2}$ body surface. After 24 hours, the animals were sacrificed and organs harvested. Complete organs of liver, lung, kidneys, and a muscle tissue sample were processed and treated in a $100 \mathrm{~mL}$ glass flask (Duran, Germany) with the respective amount of extraction solution increased to the amount for the weight of the entire organ as described above followed by SPE.

3.5. Suitability of the Method to Quantify Ferrofluid-Bound MTO. The application of this newly developed method has been proven suitable in a starting in vivo pilot study with New Zealand White rabbits. First experiments with ferrofluid-bound MTO showed that the highest enrichment could be found in the kidneys. The results exhibited the wide range of MTO amounts in different tissues and proved the suitability of the method for different kinds of biological materials (Table 5).

\section{Discussion}

To the best of our knowledge, none of the existing protocols, concerning the analysis of mitoxantrone in tissues, have been feasible for our approach of ferrofluid-bound MTO. Moreover, there is especially a lack of techniques to detect small amounts in large scaled tissues. With our method connecting efficient extraction procedures with enrichment strategies towards detectable extraction solutions, we are able to perform biodistribution studies. Monitoring MTO enrichment in different tissues in case of FF-bound drug delivery and overlapping the results with magnetorelaxometric measurements, complex biodistribution patterns after application of MTO-bound iron oxide nanoparticles become low hanging fruits. Current developments in chemotherapy increasingly base on nanoscaled delivery systems. Nanoparticles, liposomes, encapsulations, micelles, and other nanostructures carrying chemotherapeutics require newly developed or modulated analytical methods. With this protocol in hand further detailed analytical instructions can be developed for adsorptive drug delivery systems using well-established and prevalent applied HPLC.

\section{Conclusion}

Here we present an easy-to-perform and versatile applicable new method to determine even small amounts of mitoxantrone, regardless if it is in pure or ferrofluid-bound condition in tissues or other biological matrices. Established procedures have not been useful in our context to detect mitoxantrone, especially in presence of $\mathrm{FF}$ and contained in tissue samples weighing more than $100 \mathrm{~g}$ which especially is necessary for medical application studies in cancer research. We applied this method to evaluate the biodistribution of MTO in rabbit tissue. Within first experiments, we could easily perform the measurements of whole organs and showed the applicability of this new method and its widespread possibilities and analytical applications.

\section{Acknowledgments}

These studies were supported by Else Kröner-FreseniusFoundation, Bad Homburg, Germany and Deutsche Forschungsgemeinschaft (DFG-AL 552/3-1), Germany. Moreover, the authors like to thank Waters, Varian, Macherey \& Nagel, and Merck for the generous appropriation of cartridge samples as well as Mr Gereon Biermann (Dionex) to allocate them the ASE 200 (Dionex) for experimental series.

\section{References}

[1] R. Jurgons, C. Seliger, A. Hilpert, L. Trahms, S. Odenbach, and C. Alexiou, "Drug loaded magnetic nanoparticles for cancer therapy," Journal of Physics Condensed Matter, vol. 18, no. 38, pp. S2893-S2902, 2006.

[2] C. Alexiou, R. Jurgons, C. Seliger, O. Brunke, H. Iro, and S. Odenbach, "Delivery of superparamagnetic nanoparticles for local chemotherapy after intraarterial infusion and magnetic drug targeting," Anticancer Research, vol. 27, no. 4, pp. 20192022, 2007.

[3] C. Alexiou, W. Arnold, R. J. Klein, et al., "Locoregional cancer treatment with magnetic drug targeting," Cancer Research, vol. 60, no. 23, pp. 6641-6648, 2000.

[4] C. Alexiou, R. Jurgons, C. Seliger, and H. Iro, "Medical applications of magnetic nanoparticles," Journal of Nanoscience and Nanotechnology, vol. 6, no. 9-10, pp. 2762-2768, 2006. 
[5] M. E. Fox and P. J. Smith, "Long-term inhibition of DNA synthesis and the persistence of trapped topoisomerase II complexes in determining the toxicity of the antitumor DNA intercalators mAMSA and mitoxantrone," Cancer Research, vol. 50, no. 18 , pp. 5813-5818, 1990.

[6] J. Kapuscinski and Z. Darzynkiewicz, "Condensation of nucleic acids by intercalating aromatic cations," Proceedings of the National Academy of Sciences of the United States of America, vol. 81, no. 23, pp. 7368-7372, 1984.

[7] D. Faulds, J. A. Balfour, P. Chrisp, and H. D. Langtry, "Mitoxantrone. A review of its pharmacodynamic and pharmacokinetic properties, and therapeutic potential in the chemotherapy of cancer," Drugs, vol. 41, no. 3, pp. 401-449, 1991.

[8] J. M. Fidler, S. Q. DeJoy, and J. J. Gibbons Jr., "Selective immunomodulation by the antineoplastic agent mitoxantrone. I. Suppression of B lymphocyte function," Journal of Immunology, vol. 137, no. 2, pp. 727-732, 1986.

[9] J. M. Fidler, S. Q. DeJoy, F. R. Smith III, and J. J. Gibbons Jr., "Selective immunomodulation by the antineoplastic agent mitoxantrone. II. Nonspecific adherent suppressor cells derived from mitoxantrone-treated mice," Journal of Immunology, vol. 136, no. 8, pp. 2747-2754, 1986.

[10] F. Wiekhorst, C. Seliger, R. Jurgons, et al., "Quantification of magnetic nanoparticles by magnetorelaxometry and comparison to histology after magnetic drug targeting," Journal of Nanoscience and Nanotechnology, vol. 6, no. 9-10, pp. 32223225, 2006.

[11] C. Seliger, R. Jurgons, F. Wiekhorst, et al., "In vitro investigation of the behaviour of magnetic particles by a circulating artery model," Journal of Magnetism and Magnetic Materials, vol. 311, no. 1, pp. 358-362, 2007.

[12] J. Catalin, A. F. Peloux, F. Coloma, et al., "Direct determination of mitoxantrone in plasma by high performance liquid chromatography using an automatic precolumn-switching system as sample clean-up procedure," Biomedical Chromatography, vol. 8, no. 1, pp. 37-41, 1994.

[13] L. Slordal, A. Andersen, and D. J. Warren, "A sensitive and simple high-performance liquid chromatographic method for the determination of mitoxantrone in plasma," Therapeutic Drug Monitoring, vol. 15, no. 4, pp. 328-333, 1993.

[14] M. J. Priston and G. J. Sewelfe, "Improved LC assay for the determination of mitozantrone in plasma: analytical considerations," Journal of Pharmaceutical and Biomedical Analysis, vol. 12, no. 9, pp. 1153-1162, 1994.

[15] C. P. Luftensteiner, I. Schwendenwein, B. Paul, H. G. Eichler, and H. Viernstein, "Evaluation of mitoxantrone-loaded albumin microspheres following intraperitoneal administration to rats," Journal of Controlled Release, vol. 57, no. 1, pp. 35-44, 1999.

[16] K. T. Lin, G. E. Rivard, and J.-M. Leclerc, "High-performance liquid chromatographic determination of mitoxantrone in plasma utilizing non-bonded silica gel for solid-phase isolation to reduce adsorptive losses on glass during sample preparation," Journal of Chromatography, vol. 465, no. 1, pp. 75-86, 1989.

[17] K. M. Rentsch, R. A. Schwendener, and E. Hanseler, "Determination of mitoxantrone in mouse whole blood and different tissues by high-performance liquid chromatography," Journal of Chromatography B, vol. 679, no. 1-2, pp. 185-192, 1996.

[18] J. L. Johnson, A. Ahmad, S. Khan, et al., "Improved liquid chromatographic method for mitoxantrone quantification in mouse plasma and tissues to study the pharmacokinetics of a liposome entrapped mitoxantrone formulation," Journal of Chromatography B, vol. 799, no. 1, pp. 149-155, 2004.

[19] B. Lu, S.-B. Xiong, H. Yang, X.-D. Yin, and R.-B. Zhao, "Mitoxantrone-loaded BSA nanospheres and chitosan nanospheres for local injection against breast cancer and its lymph node metastases. II: tissue distribution and pharmacodynamics," International Journal of Pharmaceutics, vol. 307, no. 2, pp. 175-181, 2006.

[20] M. Hodenius, Polymer- und liposomstabilisierte ferrofluide und ihre funktionalisierung, Ph.D. thesis, Fakultät für Mathematik, Informatik und Naturwissenschaften, 2002.

[21] FDA, "Guidance for Industry Bioanalytical Method Validation," 2001, http://www.fda.gov/downloads/Drugs/GuidanceComplianceRegulatoryInformation/Guidances/ucm 122858 .pdf.

[22] J. Wellmitz and M. Gluschke, "Leitlinie zur Methodenvalidierung," 05-01, 2005.

[23] B. Klejdus, J. Vacek, V. Adam, et al., "Determination of isoflavones in soybean food and human urine using liquid chromatography with electrochemical detection," Journal of Chromatography B, vol. 806, no. 2, pp. 101-111, 2004.

[24] F. J. Moreno, A. Olano, G. Santa-Maria, and N. Corzo, "Determination of maltodextrins in enteral formulations by three different chromatographic methods," Chromatographia, vol. 50, no. 11-12, pp. 705-710, 1999.

[25] G. A. Shabir, "Validation of high-performance liquid chromatography methods for pharmaceutical analysis: understanding the differences and similarities between validation requirements of the US Food and Drug Administration, the US Pharmacopeia and the International Conference on Harmonization," Journal of Chromatography A, vol. 987, no. 1-2, pp. 57-66, 2003. 

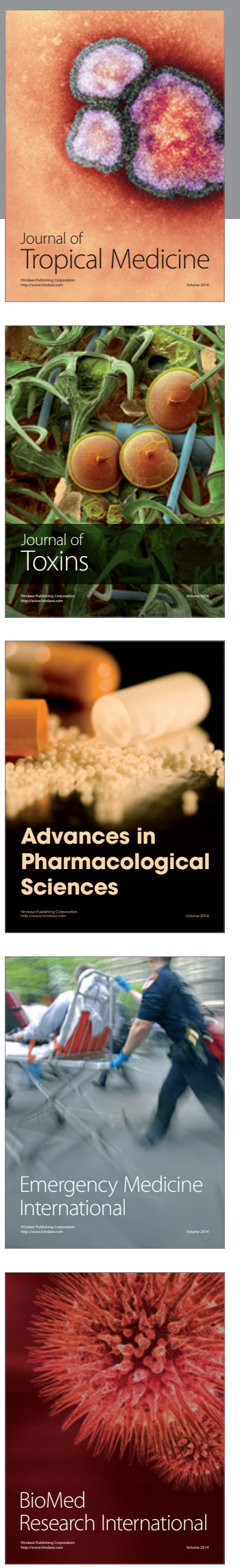
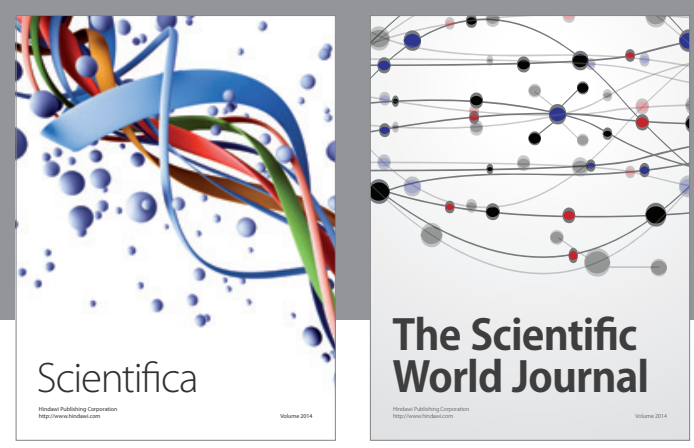

The Scientific World Journal
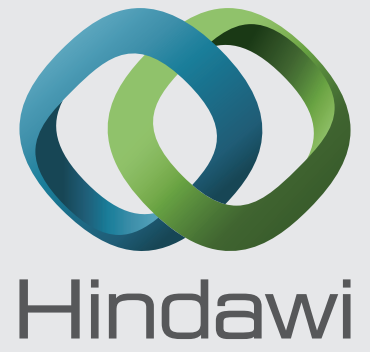

Submit your manuscripts at

http://www.hindawi.com
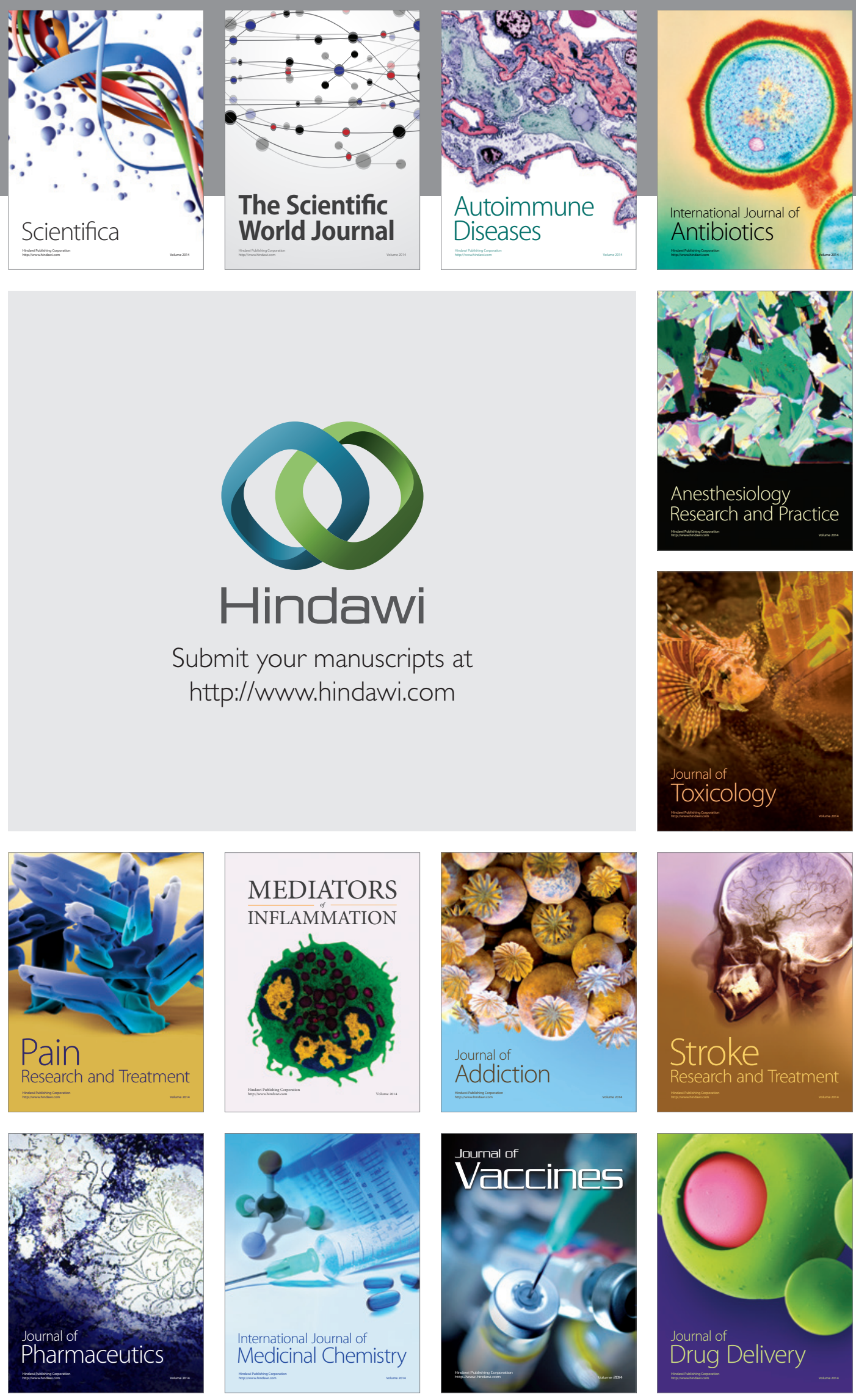